\title{
SEISMIC BEHAVIOUR OF BEAM-COLUMN SUB-ASSEMBLAGES DESIGNED FOR TWO LEVELS OF GRAVITY LOADS
}

\author{
A.Kanchana Devi ${ }^{1}$, Saptarshi Sasmal ${ }^{2}$, K.Ramanjaneyulu ${ }^{3}$ \\ ${ }^{1}$ Academy of Scientific and Innovative Research, CSIR-Structural Engineering Research Centre, Chennai, India, \\ ${ }^{2}$ Academy of Scientific and Innovative Research, CSIR-Structural Engineering Research Centre, Chennai, India, \\ ${ }^{3}$ Academy of Scientific and Innovative Research, CSIR-Structural Engineering Research Centre, Chennai, India, \\ kanchana@serc.res.in,saptarshi@serc.res.in,rams@serc.res.in
}

\begin{abstract}
An exterior jointof a typical three storied three bay reinforced concrete (RC) Framed building isconsidered forthe study. The frameisdesigned for the combination of dead load and live loads. Depending on the load level, there is a possibility of providing either singly reinforced (SP1) or doubly reinforced (SP1-D) section for beams at the joint. For gravity load designed specimens which require singly reinforced section for beams, bottom reinforcement bars are curtailed as required. For higher gravity designed specimens which require doubly reinforced section for beam, bottom reinforcement bars are to be provided with required anchorage beyond the face of the column.The beam-column sub-assemblages designed for two levels (normal and higher) are subjected to seismic type of loading and load-displacement hysteresis, energy dissipation, strength and stiffness degradation of the specimens are compared. The cumulative energy dissipation of specimen SP1-D is 37\% higher than that of SP1.The specimens SP1-D and SP1 have shown almost same level of stiffness degradation in negative cycles. In positive cycle, SPI have undergone more stiffness degradation than SP1-D.The maximum strength degradation of SP1-D and SP1 in positive cycles is found to be $37 \%$ and $34 \%$ respectively. In negative cycles, maximum strength degradation is $29 \%$, and $23 \%$ respectivelyfor SP1-D and SP1.
\end{abstract}

Keyword: Beam-column sub-assemblage, Gravity load designed, Energy dissipation, Strength degradation, Stiffness degradation, Hysteresis - ****

\section{INTRODUCTION}

Most of the older buildings were designed only for gravity loads. The past earth quakes produced devastating damages to the gravity load designed structures. It is also observed that the beam-column joints are the crucial components of framed structure under seismic loading. The degradation of the joint under seismic activity/ seismic type of loading results in hindering the force flow from the beam to the column. Hence, it is to essential evaluate seismic performance of joints in order to avoid catastrophic collapse of buildings.

There are lot of existing structures, which were designed only for gravity loads whose seismic performance is questionable due to inadequate reinforcement, improper detailing, and lack of confinement. Hence, several researchers investigated the seismic performance of non-seismically designed structures and on different detailing practices, which improve the seismic performance of the beam-column joint. Aycardi et al (1994) investigated the behaviour of gravity load designed columns and beam column sub-assemblages (both exterior and interior) under seismic type of loading. It was reported that the exterior sub-assemblages experienced weak beam and strong column failure whereas the interior beam column sub-assemblages showed strong beam and weak column failure. It was also reported that the failures of the columns under different axial loads are governed by flexural mode of failure. A gravity load collapse mechanism of RC frames was investigated by Elwood and Moehle (2002) using shake table test to observe the process of failure due to dynamic shear and axial load. The $\mathrm{RC}$ frame was characterized by low ductile columns with a predominant shear failure mode which is found to accelerate the lateral strength degradation process. It was concluded that axial stress on the column influences the behavior of the column during shaking, particularly after shear failure. Dhakal et al. (2005) carried out an experimental study on dynamic response of GLD RC connections(according to British Standard BS 8110-1985). It was observed that, though the connection zones are most important parts in dissipating energy during earthquake, most of the GLD connections are weaker than the adjoining structure and failed in shear.A comparative study on seismic behavior of columns in ordinary- and intermediate- moment resisting frames (according to ACI 318-02) was carried out by Han and Jee (2005). It was pointed out that all the ordinary and intermediate moment resisting frames have strength greater than that specified by ACI 318 and show considerably high drift capacity. 
Hence in the present study,an exterior jointof a typical three storied three bay RC Framed building with $6 \mathrm{~m}$ span in one direction and $4 \mathrm{~m}$ span in the other orthogonal direction and $3.5 \mathrm{~m}$ floor height each istaken for study. Beams and columns are designed for the combination of dead load and live loads but the higher load demands are considered for higher gravity load designed specimens. The beam-column sub-assemblages are subjected to simulated seismic type of loading.The seismic performance is evaluated in terms of load-displacement, energy dissipation, strength and stiffness degradation.

\section{Details of the Specimen}

A typical three storied RC Framed building with $6 \mathrm{~m}$ span and $3.5 \mathrm{~m}$ each floor height is taken up for the study. A $3 \mathrm{D}$ model of the building is created using standard software package. The support conditions are assigned as fixed at the bottom of the column. The liner elastic analysis is performed. An exterior jointwithout transverse beams of a typical three storied RC is chosen for investigation. Beams and columns are designed for the combination of dead load and live loads but the higher load demands are considered for higher gravity load designed specimens.For gravity load designed specimens beam bottom bars project straight into the joint region and for higher gravity designed specimens beam bottom bars are provided with compression anchorages. The cross section dimensions of $300 \mathrm{~mm} \times 400 \mathrm{~mm}$ and $300 \mathrm{~mm} \times 300 \mathrm{~mm}$ are adoptedfor beam and column respectively for all the specimens and the reinforcement details of the specimen are as shown Figs 1 and 2.The general dimensions of beam-column sub-assemblage are as follows: height of column is $3800 \mathrm{~mm}$ and length of beam is $1700 \mathrm{~mm}$.

The specimens are instrumented extensively by affixing strain gages at critical locations identified on the reinforcement bars. Strain gages areaffixed on the main reinforcement bars of the beam near the junction upto the distance'd', i.e. the depth of the beam and on the column main bars, column ties and beam stirrups. The concrete of mix proportions 1:1.695:3.013 with water cement ratio of 0.5 is used to ensure better workability of concrete. The specimens are cast and are cured for 28 days using wet curing. The concrete cubes and cylinders that were cast along with the specimen were tested.Average compressive strength and split tensile strength of concrete are presented in Table 1 .

\section{Experimental Investigations}

The test setup is arranged on the test floor so that the beamcolumn joint is positioned horizontally parallel to the floor and the cyclic load is applied in the plane of the test floor. The schematic diagram of test set-up and positioning of test specimen is shown in the Fig.3.An axial load of $300 \mathrm{kN}$ is applied to the column by hydraulic jack at one end of the column against the reaction block at the other end.The level of axial load in column was arrived by analysis of the global system of the three storey four bay building. The lateral load was applied on the beam tip in displacement control mode using $25 t$ actuator, according to the load history shown in Fig. 4. Reverse cyclic load is applied in terms of drift ratio (\%) of the component where the drift is calculated asper equation (1).

Drift ratio $(\%)=\left(\Delta \mathrm{l} / \mathrm{l}_{\mathrm{b}}\right) * 100$

Where, $\Delta l$ and $l_{b}$ are the applied displacement at the beam tip and the length of the beam from columnface to the application point of the displacement respectively. Three complete cycles are applied for each drift ratio.Reverse cyclic displacements of equal magnitude are applied on all the specimens, where positive drift produces tension in the beam bottom and negative drift produces tension in beam top. The test was stopped when the load dropped either in the positive or negative drift ratio by $50 \%$ of that maximum load.

\section{Behavior of Specimen}

Reverse cyclic displacements of equal magnitude are applied on all the specimens, where positive drift produces tension in the beam bottom and negative drift produces tension in beam top. During first cycle of $\pm 0.367 \%$ drift ratio in SP1, flexural cracks appeared at face of joint in the beam bottom and beam top as soon as tensile stresses exceeded cracking stresses in specimen SP1 as shown in Fig 5a. With further increase in drift, the flexural cracks spread along the length of the beam at both positive and negative cycles. At drift ratio of $\pm 1.47 \%$, joint shear cracks appeared along both diagonals of the joint.At drift ratio of $+1.47 \%$, a prominent crack appeared at the joint face propagated to the complete depth of beam with a crack width of $3 \mathrm{~mm}$ due to loss of bond between bottom reinforcement and concrete which is evident from the drop in strain of the bottom reinforcement. Upon further drift increment, the crack at joint face widened during positive cycles, at a drift ratio of $2.94 \%$ the crack width measured is $3 \mathrm{~mm}$. The joint shear cracks along the diagonal connecting beam bottom and column outer got widened and propagated into the column D-region of the column during the negative cycles. The joint shear cracks developed and propagated during negative cycle rather than positive cycle as shown in Fig $5 b$.

For specimen SP1-Dduring the positive drift ratio of $0.367(\%)$, flexure cracks appeared in the beam bottom whereas the flexural cracks are formed on top face of the beam at drift ratio of $0.735(\%)$. With the further drift increment shear cracks are appeared along both diagonals of the joint at drift ratio of $1.47 \%$. As soon as the yielding of reinforcement commences, the damages got shifted towards the joint as the joint does not possess enough shear resistance to cater for the huge shear demand imposed on the joint due to seismic type of loading. At drift ratio of $2.2(\%)$, fine flexural cracks are observed on the outer face of column and with further increase in drift the existing cracks in the joints got widened.The maximum crack width of $10 \mathrm{~mm}$ is observed at the final stage 
of loading. The crack pattern observed during positive and negative cycles at drift ratio of $3.67 \%$ is as shown in Fig 6.

\section{Results and Discussions}

\section{Load Displacement hysteresis}

The load versus displacement curves obtained from reverse cyclic test on specimens SP1, and SP1-D are depicted in Figs 7 and 8 respectively. From the load displacement hysteresis curve, it is evident that Specimen SP1 which was designed only for gravity loads exhibited poor seismic performance when compared to SP1-D, which was due to lack of anchorage and inadequate reinforcement at beam bottom. The maximum load carried by Specimen SP1 during the positive cycle is $54 \%$ of maximum load of the negative cycle. In the positive cycle of specimen SP1, the load dropped at the displacement cycle of $25 \mathrm{~mm}$ due to the slippage of beam bottom reinforcement. In the negative cycle of specimen SP1, the load increases with the displacement until the yielding of beam top reinforcement. Beyond which global strength degradation behavior is observed due to extensive damage of joint region with drift increment. Specimen SP1-D show cased better performance compared to that of SP1 as the yielding of beam reinforcement occurred in both positive and negative cycles. Specimen SP1D sustained up to the displacement level of $62.5 \mathrm{~mm}$ whereas the SP-1 sustained up to $50 \mathrm{~mm}$ displacement at the beam tip. Further, sudden bond failure is not observed in the SP1-D in contrast to that observed in SP1. The specimen SP1-D showed uniform strength degradation behaviour in both positive and negative cycles whereas specimen SP1 showed sudden drop in load during positive cycles.

The load-displacement envelope curves obtained for specimens SP1 and SP1-D are compared in Fig 9. During positive cycles up to the displacement of $+12.5 \mathrm{~mm}$, maximum load carried by SP1 and SP-D are almost same. Beyond the displacement level of $12.5 \mathrm{~mm}$ SP-1 incurred huge strength degradation this could be witnessed from Fig 9. During negative cycles, both specimens carried same load up to a displacement of $25 \mathrm{~mm}$ and after that SP1-D carried higher load the SP1 and also undergone larger displacements. The maximum loads carried by SP1-D are $22 \%$ and $7 \%$ higher than SP1in positive and negative cycles. SP1-D showcased better performance compared to SP1.

\section{Energy Dissipation}

The energy dissipation is the crucial performance parameter as the energy imparted to system during earthquake has to be dissipated by the system. The cumulative energy dissipation capacity of specimen is shown in Fig 10. The specimen SP1 and SP1-D dissipated almost same energy till the drift ratio of $2.2 \%$.At the drift ratio of $2.94 \%$ cumulative energy dissipated by SP1 is $11 \%$ lower than SP1-D. The cumulative energy dissipated by specimen SP1-D is 37\% higher than that of SP1. Thus, doubly reinforced gravity load designed specimens showed remarkable improvement the energy dissipation compared to the singly reinforced section.

\section{Stiffness Degradation}

The stiffness degradation of the specimens are reported as percentage degradation of the positive / negative cycle with respect to the corresponding first cycle and stiffness of the each cycle is calculated as the slope corresponding to the maximum displacement. The stiffness degradation of the specimens is shown in Fig 11. Both specimens have undergone more than $90 \%$ of stiffness degradation before failure in both positive and negative cycles. The specimens SP1-D and SP1 have undergone almost same stiffness degradation in the negative cycle. In positive cycle SP1 have undergone more stiffness degradation than SP1-D due to separation of joint. At drift ratio of $+1.47 \%$, the stiffness of the SP1 is $25 \%$ lesser than that of the SP1-D.It is also observed that stiffness degradation in the positive cycles is more than the stiffness degradation in the negative cycle for both the specimens. At drift ratio of $2.2 \%$, stiffness degradation of first positive cycle is $10 \%$ and $21 \%$ lower than corresponding negative cycle in SP1-D and SP1 respectively.

\section{Strength Degradation}

The strength degradation in second and third cycles with respect the first cycle of each drift ratio is as shown in Fig 12. From Fig 12, it is observed that the strength degradation in the positive cycles is larger than that in the negative cycles for both the specimens. The strength degradation between second and third cycles is smaller compared to that of strength degradation between first and second cycles for both the specimens. The strength degradation of SP1 is more in both positive and negative cycles compared to that of SP1D.Maximum strength degradation of SP1-D is larger than SP1 in both positive and negative cycles. The maximum strength degradation of SP1-D and SP1 in positive cycles is 37\% and $34 \%$ respectively and in negative cycles are $29 \%$, and $23 \%$ respectively. Even though the maximum strength degradation of both specimens is nearly same the maximum strength degradation of SP1-D occurred at drift ratio of $\pm 3.67 \%$ whereas in SP1 it occurred at $+1.47 \%$ and $-2.94 \%$ in positive and negative cycle respectively.

\section{CONCLUSIONS}

An exterior jointof a typical three storied three bay RC Framed building isconsidered forthe study. The frameisdesigned for the combination of dead load and live loads. Two levels of gravity load designed specimens namely with singly reinforced and doubly reinforced section for beams at the joint are taken up and subjected to seismic type of loading and seismic performance of the specimens are evaluated. Specimen SP1-D show cased better performance compared to SP1 as the yielding of beam reinforcement occurred in both positive and negative cycles. The specimen 
SP1-D showed uniform strength degradation behaviour in both positive and negative cycles whereas specimen SP1 showed sudden drop in load during positive cycles due to bond failure of beam bottom reinforcement. Further, the maximum loads carried by SP1-D in positive and negative cycles are $22 \%$ and 7\% higher than that of SP1and also cumulative energy dissipated by specimen SP1-D is 37\% higher than that of SP1. Thus, doubly reinforced gravity load designed specimens showed remarkable improvement in the energy dissipation compared to the singly reinforced section. The maximum strength degradation of SP1-D and SP1 in positive cycles is found to be $37 \%$ and $34 \%$ respectively and in negative cycles, is $29 \%$, and $23 \%$ respectively. Thus,the present study brings into light the seismic vulnerability of gravity load designed and better performance of higher gravity load designed specimens. Specimen SP1-D which is designed for higher gravity loads exhibit relatively better seismic performance than singly reinforced gravity load designed specimens.

\section{Acknowledgement}

This paper is being published with the kind permission of the Director, CSIR-SERC, Chennai.

\section{REFERENCES}

[1] Aycardi, L.E., Mander, J.B. and Reinhorn, A.M., "Seismic resistance of reinforced concrete frame structures designed only for gravity loads: Experimental performance of sub assemblages", ACI Structural Journal, V. 91, No.5, 1994, pp 552-563

[2] Elwood, K. J. and Moehle, J. P., "Shake Table Tests on The Gravity Load Collapse of Reinforced Concrete Frames", Seventh US National Conference on Earthquake Engineering, Boston, MA, Earthquake Engineering Research Institute, July 2002.

[3] Dhakal, R.P., Pan, T.-C., Irawan, P., Tsai, K.-C., Lin, K.C. and Chen, C.-H., "Experimental Study on the Dynamic Response of Gravity-Designed Reinforced Concrete Connections", Engineering Structures, V. 27, No. 1, 2005, pp. 75-87.

[4] Han, S. W. and Jee, N.Y., "Seismic Behaviours of Columns in Ordinary and Intermediate Moment Resisting Concrete Frames", Engineering Structures, V. 27, No. 6, 2005, pp. 951-962.

Table

Table 1. Strength parameters of concrete

\begin{tabular}{|c|c|c|c|}
\hline Specimen & $\begin{array}{c}\text { Average cube compressive } \\
\text { strength ofconcrete }\left(\mathrm{N} / \mathrm{mm}^{2}\right)\end{array}$ & $\begin{array}{c}\text { Average cylinder compressive strength } \\
\text { ofconcrete }\left(\mathrm{N} / \mathrm{mm}^{2}\right)\end{array}$ & $\begin{array}{c}\text { Average split tensile strength of } \\
\text { concrete }\left(\mathrm{N} / \mathrm{mm}^{2}\right)\end{array}$ \\
\hline SP1 & 48.16 & 41.34 & 2.67 \\
\hline SP1-D & 52.71 & 41.97 & 3.2 \\
\hline
\end{tabular}

\section{Figures}

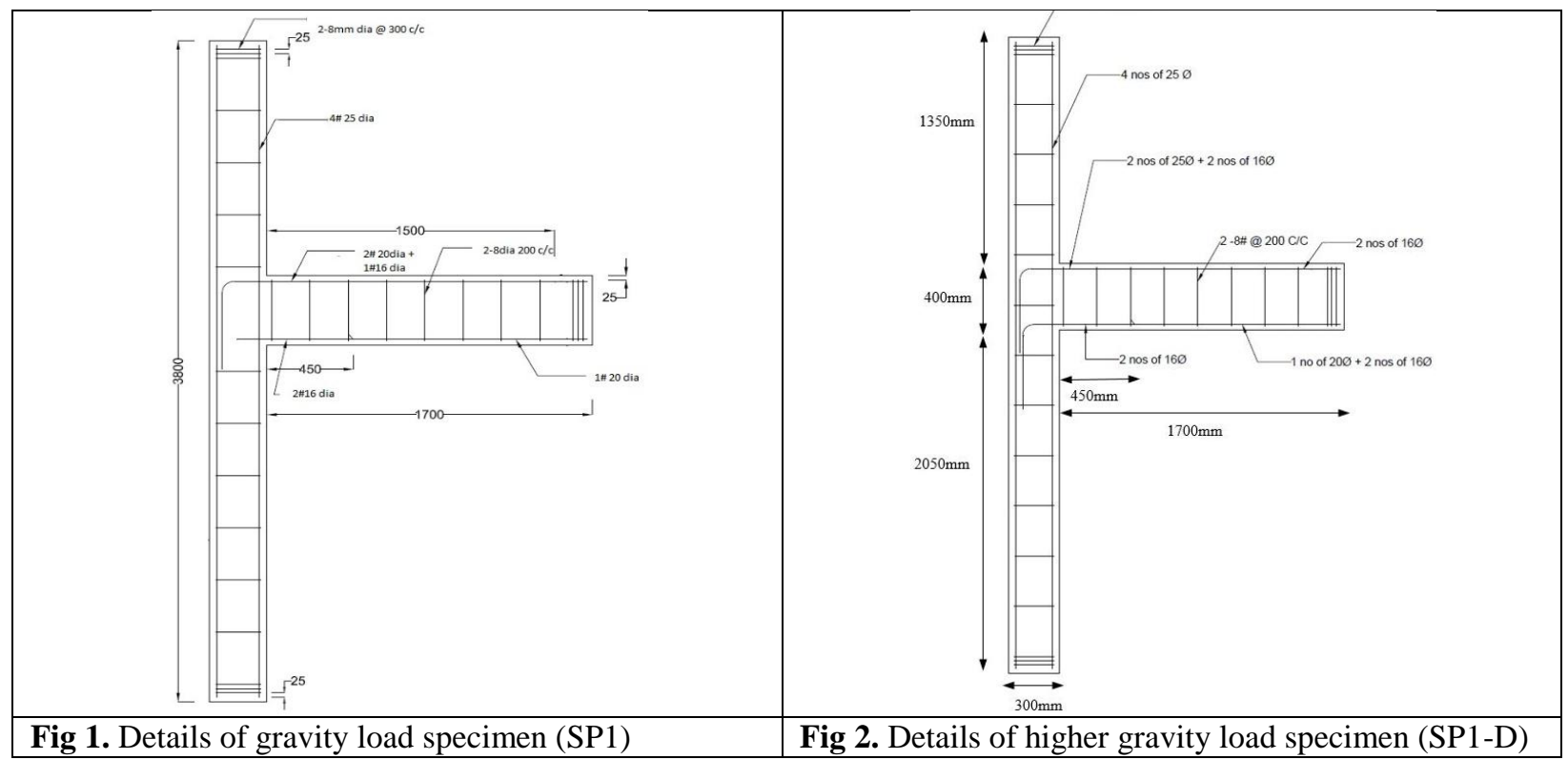



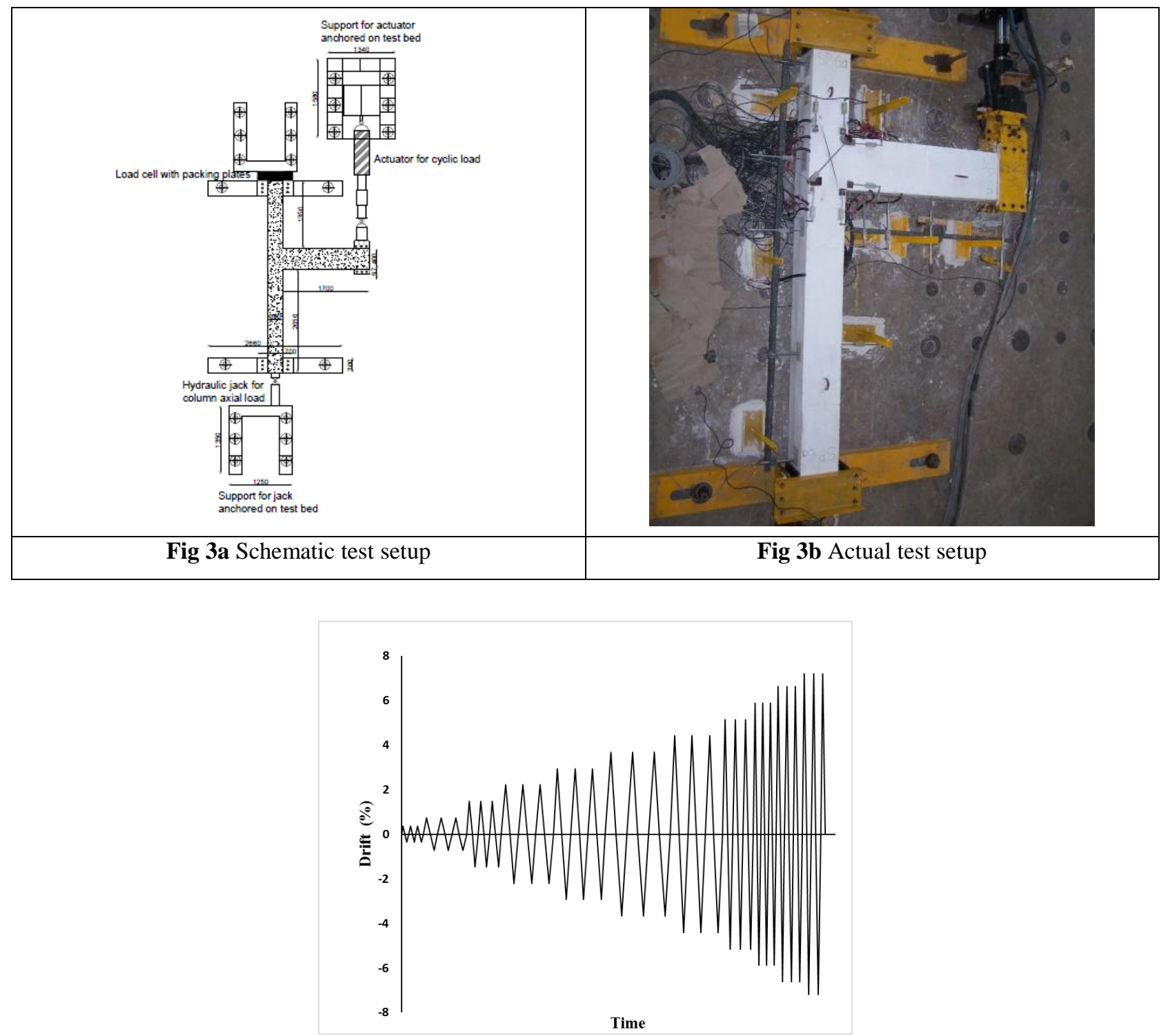

Figure 4. Reverse cyclic loading history

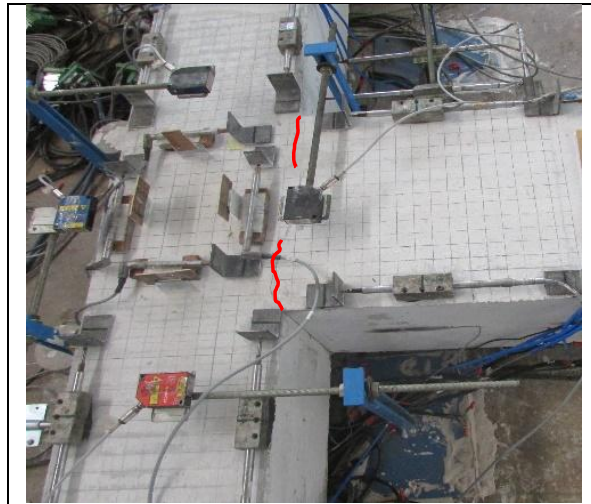

Fig 5a Flexural crack at $0.367 \%$ drift

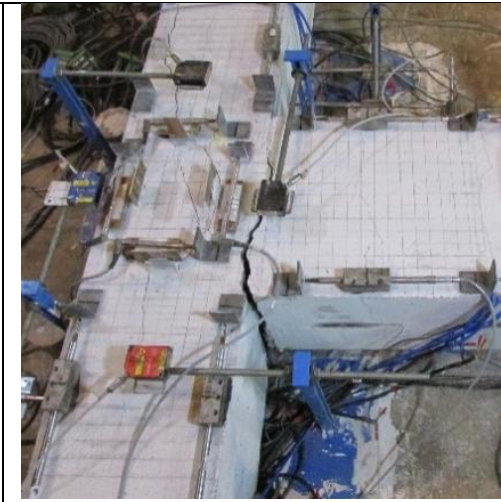

Fig 5b Crack pattern at $+2.94 \%$ (left) and $-2.94 \%$ (right) drift ratio $-\mathrm{SP} 1$

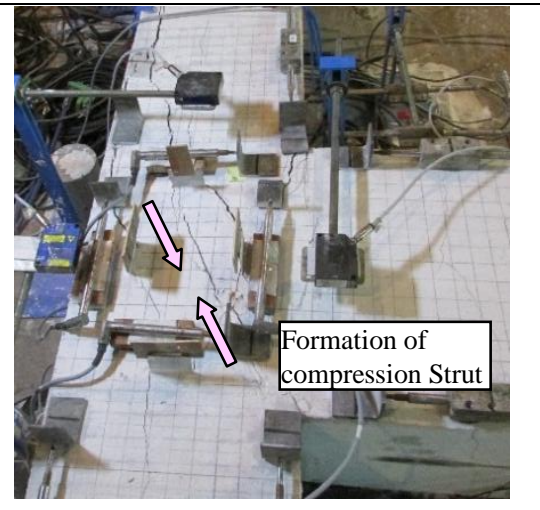
1 ratio-SP1 

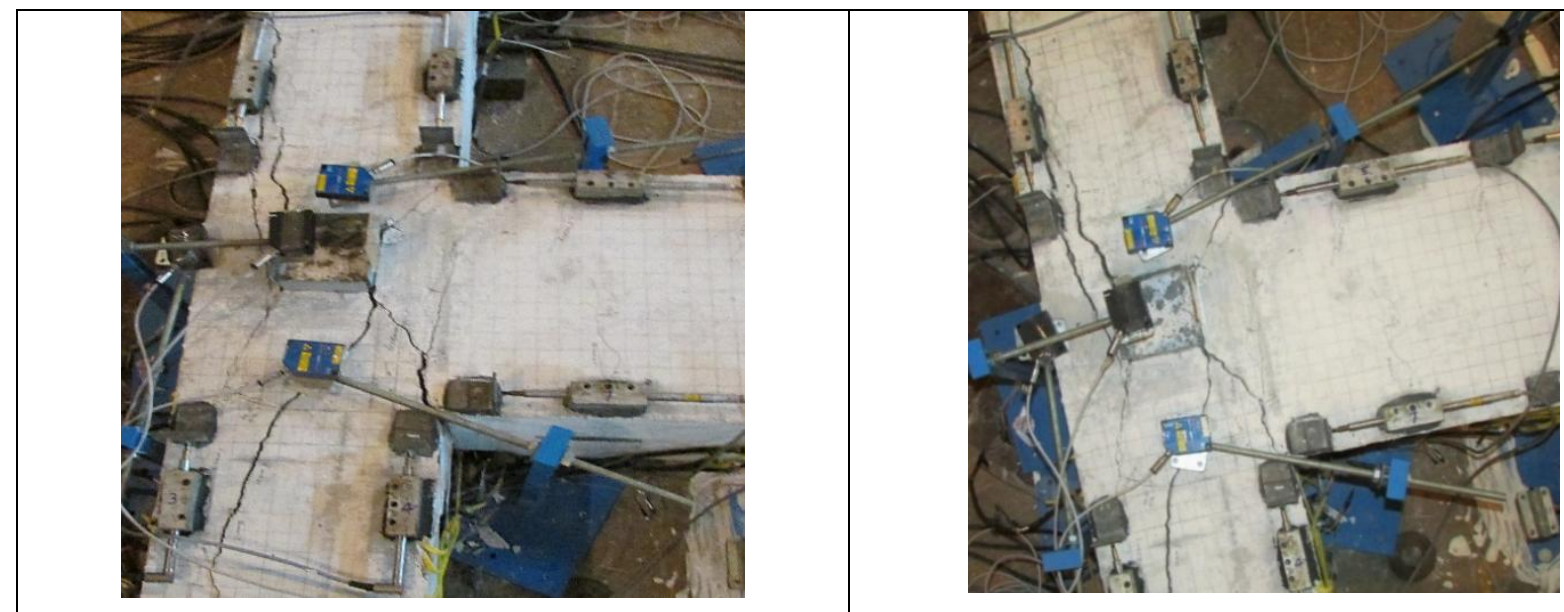

Fig 6 Crack pattern at $+3.67 \%$ (left) and $-3.67 \%$ (right) drift ratio -SP1-D

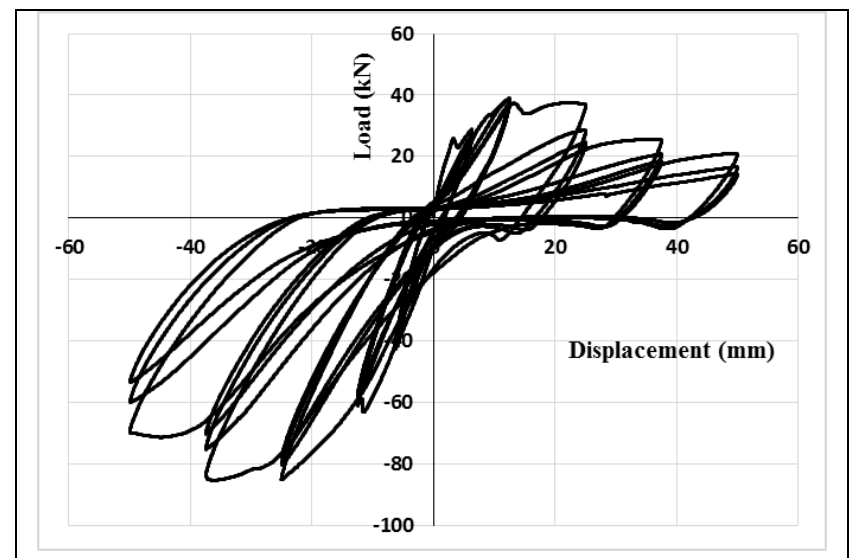

Fig. 7 Load Displacement hysteresis of SP1

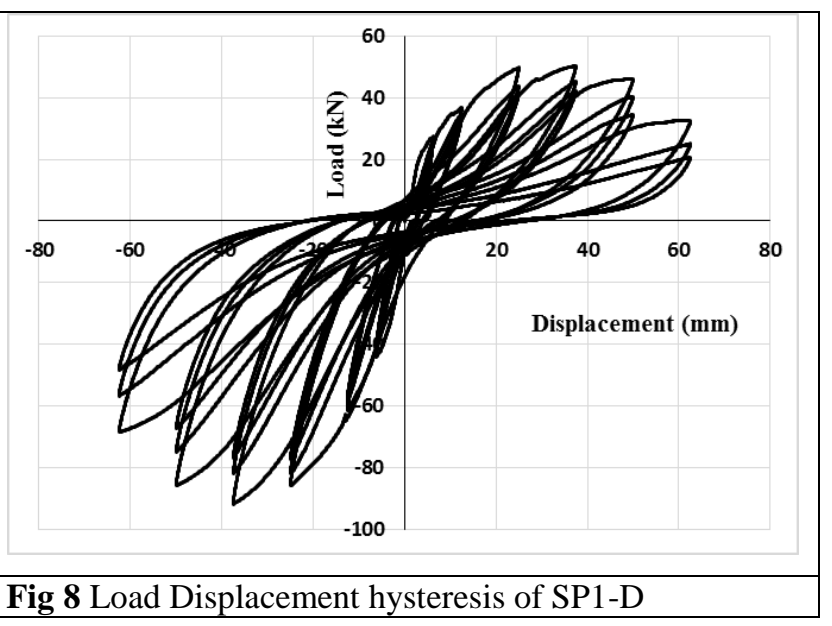

Fig 8 Load Displacement hysteresis of SP1-D

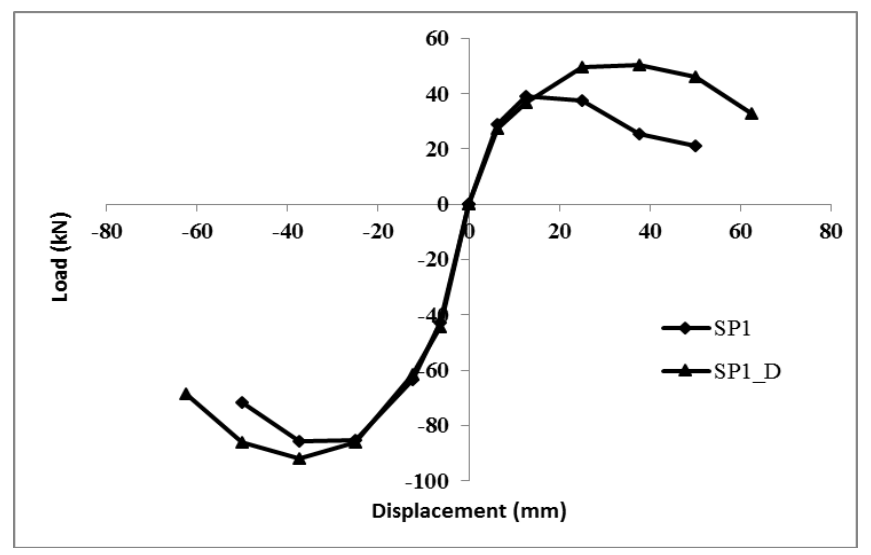

Fig. 9 Load Envelope of specimens SP1and SP1-D 


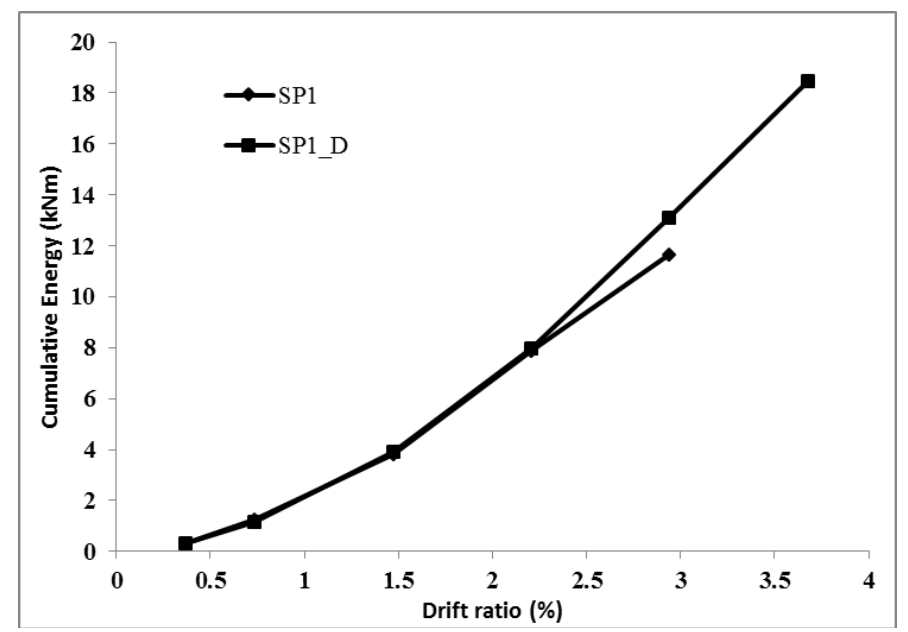

Fig 10 Cumulative energy dissipation

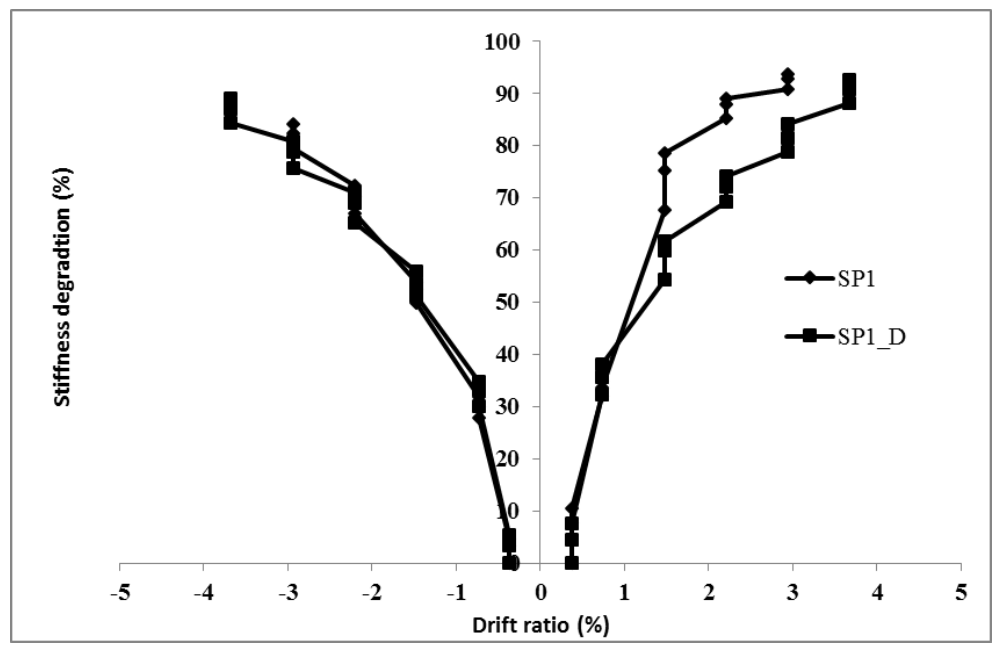

Figure 11 Stiffness Degradation of specimens

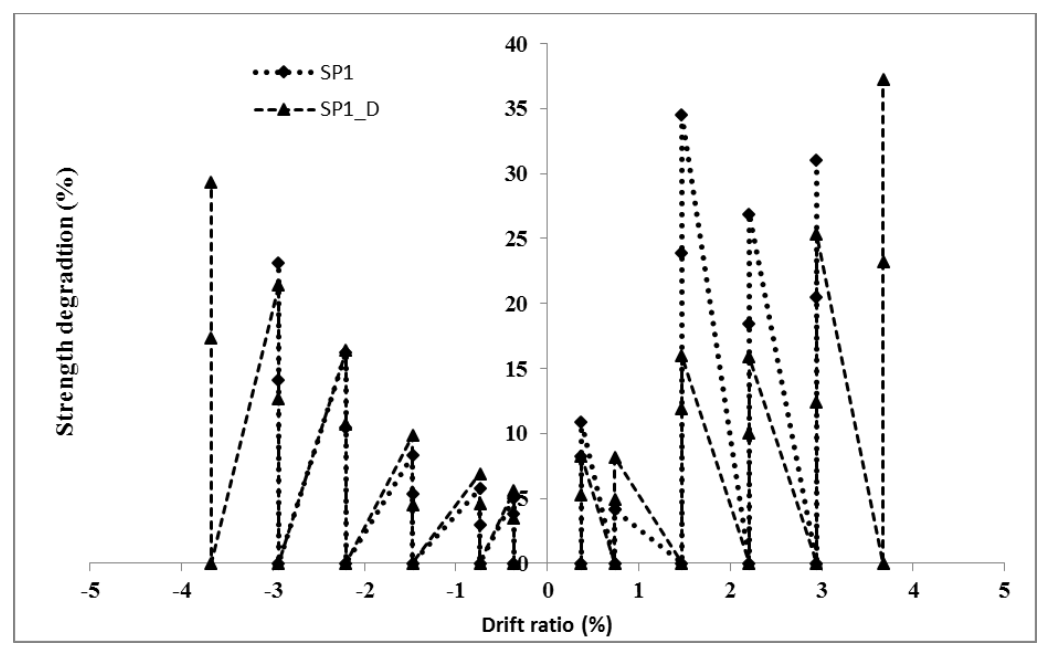

Figure 12 Strength Degradation of specimens SP1 and SP1-D 